\title{
Sources and directions of social support and life satisfaction among solitary Chinese older adults in Hong Kong: the mediating role of sense of loneliness
}

This article was published in the following Dove Press journal:

Clinical Interventions in Aging

Xue Bai'

Shuyan Yang²

Martin Knapp ${ }^{3}$

'Department of Applied Social Sciences, The Hong Kong Polytechnic University, Hong Kong, People's Republic of China; ${ }^{2}$ Department of Social Work, Hong Kong Baptist University, Hong Kong, People's Republic of China; ${ }^{3}$ Personal Social Services Research Unit, London School of Economics and Political Science, London, UK
Correspondence: Xue Bai

Department of Applied Social Sciences, The Hong Kong Polytechnic University, GH338, Hung Hom, Kowloon, Hong Kong, People's Republic of China Email xuebai@polyu.edu.hk

\begin{abstract}
Based on survey data collected from 151 community-dwelling solitary Chinese older adults in Hong Kong, the present study used path analysis to examine the mediating role of sense of loneliness in the relationship between different sources and directions of social support and life satisfaction. The results showed that sense of loneliness mediated the effects of support from families, friends, and support for others on life satisfaction. In addition, a formal source of social support was not associated with life satisfaction among solitary older adults, although those with a more secure financial status had greater overall life satisfaction. These findings highlight the importance of enhancing awareness among social and health care service providers about the negative effects of insufficient social support on older adults' sense of loneliness and life satisfaction. Family and friendship networks should be expanded for solitary older adults. Keywords: life satisfaction, path analysis, solitary older adults, sense of loneliness, social support
\end{abstract}

\section{Introduction}

Life satisfaction is defined as individuals' subjective evaluation of their overall quality of life. ${ }^{1,2}$ As a crucial indicator of subjective well-being, life satisfaction plays an essential role in the process of aging. Older people who have higher levels of life satisfaction are more likely to experience positive affect, enjoy superior physical and mental health statuses, and achieve successful aging. The results of a longitudinal survey conducted in Taiwan revealed that living alone and low life satisfaction were key risk factors of late-life depression among older adults. ${ }^{3}$ Low life satisfaction was also found to predict 5-year mortality in a sample of 1,751 community-dwelling older Canadians. ${ }^{4}$ Because factors such as impaired health, declining cognitive abilities, and diminishing social networks continually threaten the well-being of older people, improving older adults' life satisfaction is a persistent challenge. ${ }^{5,6}$

Empirical research has consistently shown that social support and steady relationships with family members, relatives, friends, and the community can promote feelings of bonding; buffer negative impacts of old-age stressors such as illness, functional limitations, and other life challenges that may occur in later life; improve self-perception; alleviate the sense of loneliness; generate happiness; and boost overall life satisfaction among older adults. ${ }^{2,7-14}$ For instance, Guo found that childless older adults in rural China who had limited access to social support were more likely to feel 
dissatisfied with their lives than those who received sufficient social support. ${ }^{15}$ However, a meta-analysis of interventions aimed at reducing sense of loneliness revealed inconsistent findings with regard to the effectiveness of social support interventions. ${ }^{16}$

Social support refers to "perceived or actual instrumental and/or expressive provisions supplied by the community, social networks, and confiding partners". ${ }^{17}$ Scholars have conceptualized social support from four main related perspectives: actual utilization or perceived availability of support, support networks (eg, family, friends, significant others, community), content (eg, financial, emotional, daily activities), and directions (eg, receiving or giving). ${ }^{11,18,19}$ Recent studies have found that both receiving support from and providing support to adult children or grandchildren can improve the family status of older adults, increase their selfesteem and feelings of commitment to others, and enhance their life satisfaction..$^{20,21}$ In addition, the size of older adults' social networks, their frequency of contact with relatives and friends, and the support received from children have all been found to be negatively associated with the sense of loneliness, possibly because sense of loneliness usually stems from feelings of being isolated from significant relationships and being rejected by others. ${ }^{18,22}$ Sense of loneliness, which is characterized by feelings of depression and anxious response to social isolation, ${ }^{23}$ is a distressing problem faced by many older adults. ${ }^{24}$ Risk factors for sense of loneliness in old age include living alone, older age, female gender, lower levels of education, and fewer financial resources. ${ }^{24-29}$ One study on widowed older people showed that supportive personal relations reduced the sense of loneliness; ${ }^{9}$ other studies have further noted that, when feelings of sense of loneliness are alleviated, individuals are more likely to have improved health outcomes and greater life satisfaction. ${ }^{30,31}$

Crucially, traditional Chinese culture respects and values the contributions of older people, leading many to assume that Chinese older adults enjoy harmonious family relations and prestigious social status, and benefit from family support. However, the traditional sources of social support (ie, adult children and spouses) can no longer be taken for granted due to changing family structures, values, and dynamics in Chinese societies including Hong Kong. ${ }^{32-34}$ The proportion of older adults in Hong Kong living together with their adult children had declined from $56.8 \%$ in 2001 to $51.2 \%$ in 2011 , corresponding to an increasing proportion of older people who live with their spouse only (ie, from 18.4\% in 2001 to $23.6 \%$ in 2011), or who live alone in the community (ie, from $11.3 \%$ in 2001 to $12.7 \%$ in 2011). ${ }^{35}$ Because solitary (ie, living alone) older adults are more likely to have inadequate social networks or access to social support, they are more vulnerable to feelings of sense of loneliness and low life satisfaction..$^{24,36}$ According to intersectionality theory, ${ }^{37,38}$ this vulnerability can be multiplied when they are subject to a combination of barriers in later life, including poor health, insufficient financial resources, or limited access to social support. Therefore, the situation of this distinct group of older people merits attention and investigation.

There is ample evidence of the associations between 1) social support and life satisfaction, 2) social support and sense of loneliness, and 3) sense of loneliness and life satisfaction among older adults. Although some scholars have begun to examine the mediating role of sense of loneliness in the relationship between social support and subjective well-being of older adults, ${ }^{39,40}$ it remains unclear whether and to what extent sense of loneliness acts as a mediator on the relationships of these different sources and directions of social support and life satisfaction among solitary older adults. Therefore, to identify the multisource and multidirectional paths of social support that influence life satisfaction through sense of loneliness, we constructed a structural mediation model based on the survey data collected from a sample of 151 solitary Chinese older adults in Hong Kong. The following two hypotheses were proposed: 1) social support - including receiving support from family, friends, and community, and providing support to others - is positively associated with life satisfaction; and 2) the relationship between social support (including different sources and directions of social support) and life satisfaction is mediated by the sense of loneliness.

\section{Methods \\ Participants}

A convenience sampling strategy was used for recruiting eligible participants. Invitation letters stating the scope and purpose of this study were either emailed or mailed to various senior service organizations on Hong Kong Island, and in Kowloon and New Territories, inviting them to help identify potential participants. Six District Elderly Community Centers and Neighborhood Elderly Centers agreed to offer assistance. Participants who were 65 years old or older, were permanent residents of Hong Kong, lived alone, and were cognitively capable of answering survey questions were included. A face-to-face questionnaire survey was conducted with 156 participants on site at the participating service organizations, and 151 completed the questionnaires were returned. Five cases were excluded due to the participants' severe hearing problems or dialect speech. 


\section{Data collection}

The questionnaire survey was conducted between January and March 2015. Ethical approval was granted from the Human Subjects Ethics Subcommittee of The Hong Kong Polytechnic University (HKPU), and consent forms were obtained from all the participants before the interviews. Five undergraduate students from the Faculty of Health and Social Sciences at HKPU conducted the interviews for this study under supervision after receiving data collection training. Each interview lasted for approximately 30 minutes.

\section{Measurements}

\section{Life satisfaction}

The five-item Satisfaction with Life Scale, originally developed by Diener et al, ${ }^{41}$ was used to assess the participants' levels of life satisfaction. The total score had a potential range of 7-35, with a higher score indicating a higher level of life satisfaction. The internal consistency of the scale in our sample, measured using Cronbach's alpha, was 0.84.

\section{Sense of loneliness}

The participants' sense of loneliness was measured using the Chinese version of the Sense of loneliness Scale, developed and validated in an older Chinese sample in Taiwan. ${ }^{42}$ In recent decades, family structure and values in Hong Kong and Taiwan have undergone similar changes. We believe that the sense of loneliness experienced by older people can be explained by shared reasons and constructed in similar ways. Therefore, this scale was used in the present study to assess sense of loneliness. This eight-item scale examined both emotional sense of loneliness (eg, "I think no one is concerned about me") and social sense of loneliness (eg, "I think I have no social activities at all"), with item scores ranging from 1 (strongly disagree) to 5 (strongly agree). The internal consistency of the scale in our sample was very satisfactory, with a Cronbach's alpha of 0.88 . The scale had a potential total score range of $8-40$, with a higher score indicating a greater sense of loneliness.

\section{Social support}

Social support was assessed using the adapted Chinese version of Lubben's Social Network Scale. ${ }^{43,44}$ This scale has been widely applied to examine various dimensions of social support for older adults; in the present study, participants were asked about different dimensions of their social networks, namely family networks, friend networks, and helping others. Family networks were measured on a six-point scale according to three items: "How many relatives do you see or hear from at least once a month?", "How often do you see or hear from that person?", and "How many relatives do you feel close to? That is, how many of them do you feel at ease with enough to be able to talk about private matters or call for help?" Friend networks were measured on a six-point scale according to three items: "Do you have any close friends? That is, do you have any friends with whom you feel at ease with enough to be able to talk about private matters or call on for help? If so how many?", "How many of these friends do you see or hear from at least once a month?", and "Tell me about the friend with whom you have the most contact. How often do you see or hear from that person?" Finally, helping others was measured by "Does anybody rely on you to something for them each day?" (5= "yes" and $0=$ "no") and "Do you help anybody with something each day?" (4= "very often"; 3 = "often"; 2 = "sometimes"; 1 = "seldom"; $0=$ "never").

Because only solitary older adults were included in the present study, the item on living arrangement was excluded. Items under each dimension of social support were summed to produce three continuous variables - namely, family networks, friend networks, and helping others - which represent different informal sources and directions of social support. The Cronbach's alpha for the scale was 0.73 in the present sample. A higher score on each subscale represents a higher level of social support from the corresponding dimension.

\section{Use of community services}

The participants' use of community services was assessed to indicate the use of social support from formal sources among solitary older adults. For this measure, the participants were asked to report whether they used community services $(1=$ "yes" and $0=$ "no").

\section{Functional health status}

The Chinese version of the seven-item Lawton Instrumental Activities of Daily Living (IADL) scale was used to assess the participants' functional health status ${ }^{45}$ which was represented by their independent capability to undertake daily activities in the previous month. In the present study, the participants were asked to rate their ability to carry out various tasks (ie, making and receiving phone calls, housekeeping, shopping, preparing food, using public transportation, taking medication, and managing personal finances). The original four-point scale ranged from 0 (independent) to 3 (totally dependent on others).$^{45}$ This score was reverse coded, with a higher score indicating a higher level of functional independency. Cronbach's alpha of the IADL scale measured in this sample was 0.74 . 


\section{Sociodemographic characteristics}

The sociodemographic information of participants, including age, gender, educational level, and financial security, was collected. Educational level was categorized as uneducated, primary level, and secondary level or above, and financial security was assessed by asking the participants to rate their financial situation as insecure, partially secure, or secure.

\section{Data analysis}

Data analyses were carried out using SPSS 21.0 and Amos 21.0.46,47 Descriptive analyses were first conducted, after which bivariate correlational analyses were performed. Only those variables that were determined to be significantly $(p<0.05)$ or marginally significantly $(p<0.2)$ correlated with sense of loneliness and/or life satisfaction were included in the subsequent path analysis. The path analysis was then used to test the mediating effect of the sense of loneliness on the relationships between different sources and directions of social support and life satisfaction. The ratio of the present sample size to the quantity of observed variables was 15:1, which is much higher than the suggested 5:1 standard. ${ }^{48}$ Missing values $(<5 \%)$ were filled in using a multiple imputation approach before testing the path models.

Normality and multicollinearity were examined. Path analysis was conducted to test both the direct and indirect effects of social support, mediated by the sense of loneliness, on life satisfaction. Bootstrapping with 2,000 replications was done, and $95 \%$ bias-corrected confidence intervals (CI) were calculated. CIs that do not contain zero represent significant indirect effects. ${ }^{49-51}$ The model fit was assessed by using $\chi^{2 /}$ $d f, p$-value, comparative fit index (CFI), goodness of fit index (GFI), Tucker-Lewis index (TLI), root mean square error of approximation (RMSEA), and standardized root mean square residual (SRMR)..$^{50}$

\section{Results}

\section{Descriptive statistics}

The descriptive statistics are presented in Table 1. Participants were between 65 and 98 years old and their mean age was 79.63 years $(\mathrm{SD}=7.77)$. The majority of the participants were female ( $85 \%)$. Nearly half of the participants were uneducated, $42 \%$ of the participants had received primary education, and only $8 \%$ had attained a secondary or higher level of education. Approximately half of the participants (46\%) rated their financial status as "partially secure", whereas nearly one-quarter (23\%) reported that they were financially insecure. The mean scores of social support from family
Table I Sociodemographic characteristics of the participants $(\mathrm{N}=|5|)$

\begin{tabular}{llll}
\hline Characteristics & N (\%) & Mean (SD) & Range \\
\hline Age & & $79.63(7.77)$ & $65-98$ \\
$\quad 65-74$ & $41(27.20)$ & & \\
$75-84$ & $65(43.00)$ & & \\
85 and above & $45(29.80)$ & & \\
Gender & & & \\
$\quad$ Male & $23(15.23)$ & & \\
Female & $128(84.77)$ & & \\
Educational level & & & \\
$\quad$ Uneducated & $75(49.70)$ & & \\
$\quad$ Primary level & $64(42.40)$ & & \\
$\quad$ Secondary level and above & $12(7.90)$ & & \\
Financial security & & & \\
$\quad$ Insecure & $35(23.20)$ & & \\
Partially secure & $69(45.70)$ & & \\
$\quad$ Secure & $47(31.10)$ & & \\
Functional health status & $151(100)$ & $19.00(2.51)$ & $10-21$ \\
Family networks & $151(100)$ & $4.63(3.89)$ & $0-12$ \\
Friend networks & $151(100)$ & $4.88(4.77)$ & $0-15$ \\
Helping others & $151(100)$ & $0.66(1.65)$ & $0-8$ \\
Use of community services & $40(26.49)$ & $0.26(0.44)$ & $0-1$ \\
Sense of loneliness & $151(100)$ & $20.70(6.85)$ & $8-40$ \\
Life satisfaction & $151(100)$ & $23.59(5.02)$ & $7-35$ \\
\hline
\end{tabular}

and friends were 4.63 (range 0-12) and 4.88 (range 0-15), respectively, and the mean score of helping others was 0.66 (range 0-8); in short, both receiving and providing social support were low among the participants. Overall, the mean scores for feelings of sense of loneliness and life satisfaction were 20.70 (range 8-40) and 23.59 (range 7-35), indicating that some participants were at risk of sense of loneliness but enjoyed a moderate level of life satisfaction.

\section{Bivariate correlations between potential predictive variables, sense of loneliness, and life satisfaction}

Bivariate correlations among the potential predictive variables (ie, age, gender, financial security, functional health status, family networks, friend networks, helping others, and the use of community services), sense of loneliness, and life satisfaction were calculated, and the results are presented in Table 2. Specifically, financial security, family networks, and friends networks were significantly associated with both sense of loneliness and life satisfaction, whereas age was significantly associated with sense of loneliness, and gender and sense of loneliness were significantly associated with life satisfaction. In addition, based on the criteria we set earlier that only those variables that were determined to be significant $(p<0.05)$ or marginally significant $(p<0.2)$ in the bivariate analyses were included in the subsequent path 
Table 2 Correlation results between study variables $(\mathrm{N}=|5|)$

\begin{tabular}{|c|c|c|c|c|c|c|c|c|c|c|}
\hline Variables & $\mathbf{I}$ & 2 & 3 & 4 & 5 & 6 & 7 & 8 & 9 & 10 \\
\hline I. Age & 1.00 & & & & & & & & & \\
\hline 2. Gender & 0.02 & 1.00 & & & & & & & & \\
\hline 3. Financial security & 0.12 & 0.02 & 1.00 & & & & & & & \\
\hline 4. Functional health status & $-0.31 * * *$ & 0.03 & 0.03 & 1.00 & & & & & & \\
\hline 5. Family networks & 0.05 & 0.13 & $0.25 * *$ & -0.06 & 1.00 & & & & & \\
\hline 6. Friends networks & -0.08 & 0.13 & 0.08 & 0.00 & $0.33^{* * *}$ & 1.00 & & & & \\
\hline 7. Helping others & -0.15 & -0.04 & 0.03 & $0.27 * *$ & 0.02 & 0.08 & 1.00 & & & \\
\hline 8. Use of community services & $0.22 * *$ & -0.12 & -0.09 & $-0.23 * *$ & -0.02 & 0.10 & -0.06 & 1.00 & & \\
\hline 9. Sense of loneliness & $\begin{array}{l}0.19^{*} \\
(0.02)\end{array}$ & $\begin{array}{l}-0.12^{\S} \\
(0.14)\end{array}$ & $\begin{array}{l}-0.20 * \\
(0.01)\end{array}$ & $\begin{array}{l}-0.03 \\
(0.76)\end{array}$ & $\begin{array}{l}-0.46 * * * \\
(0.00)\end{array}$ & $\begin{array}{l}-0.43^{* * * *} \\
(0.00)\end{array}$ & $\begin{array}{l}-0.16^{\S} \\
(0.06)\end{array}$ & $\begin{array}{l}0.02 \\
(0.81)\end{array}$ & 1.00 & \\
\hline 10. Life satisfaction & $\begin{array}{l}0.06 \\
(0.48)\end{array}$ & $\begin{array}{l}0.20^{*} \\
(0.01)\end{array}$ & $\begin{array}{l}0.44 * * * \\
(0.00)\end{array}$ & $\begin{array}{l}0.11^{\S} \\
(0.17)\end{array}$ & $\begin{array}{l}0.38^{* * * *} \\
(0.00)\end{array}$ & $\begin{array}{l}0.24 * * \\
(0.00)\end{array}$ & $\begin{array}{l}0.16^{\S} \\
(0.05)\end{array}$ & $\begin{array}{l}-0.11^{\S} \\
(0.18)\end{array}$ & $\begin{array}{l}-0.43 * * * \\
(0.00)\end{array}$ & 1.00 \\
\hline
\end{tabular}

Notes: $\S_{p}<0.2,{ }^{*} p<0.05,{ }^{* *} p<0.01$, and ${ }^{* * *} p \leq 0.001$. Numbers in parentheses indicate $p$-values for the correlations between variables.

analysis, functional health status, helping others, and the use of community services were also included for further testing in the proposed path model.

\section{Path analysis and model fit}

Table 3 and Figure 1 present the results of testing the proposed model using path analysis. In this model, life satisfaction was the dependent variable; sense of loneliness was the mediator; family networks, friends networks, helping others, and the use of community services were independent variables; and age, gender, financial security, and functional health status were background (control) variables. The nonsignificant correlations between a) independent variables, b) control variables, and c) independent variables and control variables were then removed to obtain a parsimonious model; the resulting fit indices of the proposed mediated path model were satisfactory: $\chi^{2}(22)=22.38, \chi^{2} / d f<3 ; p=0.44 ; \mathrm{CFI}=1.00$ (0.998); GFI $=1.00$ (0.973); TLI =1.00 (0.996); RMSEA =0.01; and SRMR $=0.05$. In total, the path model explained $36 \%$ of the variance in life satisfaction and $34 \%$ of the variance in the sense of loneliness.

Table 3 Direct and indirect effects of sources and directions of social support on life satisfaction ( $N=|5|)$

\begin{tabular}{|c|c|c|c|c|c|c|c|}
\hline \multirow[t]{3}{*}{ Paths } & \multicolumn{2}{|c|}{ Direct effect } & \multicolumn{2}{|c|}{ Indirect effect } & \multicolumn{2}{|c|}{ Total effect } & \multirow[t]{3}{*}{$R$-squared } \\
\hline & Beta & BC bootstrap & Beta & BC bootstrap & Beta & BC bootstrap & \\
\hline & & $95 \% \mathrm{Cl}$ & & $95 \% \mathrm{Cl}$ & & $95 \% \mathrm{Cl}$ & \\
\hline Life satisfaction & & & & & & & 0.36 \\
\hline Family networks & 0.14 & -0.01 to 0.30 & $0.09 * *$ & 0.03 to 0.18 & $0.24 * *$ & 0.09 to 0.39 & \\
\hline Friends networks & 0.05 & -0.12 to 0.19 & $0.08 * * *$ & 0.03 to 0.16 & 0.13 & -0.03 to 0.27 & \\
\hline Helping others & 0.09 & -0.03 to 0.21 & $0.03 *$ & 0.00 to 0.08 & $0.13^{*}$ & 0.01 to 0.24 & \\
\hline Use of community services & -0.06 & -0.21 to 0.08 & 0.04 & -0.03 to 0.04 & -0.06 & -0.20 to 0.08 & \\
\hline Age & 0.13 & -0.02 to 0.27 & $-0.06 * *$ & -0.14 to -0.01 & 0.07 & -0.07 to 0.21 & \\
\hline Gender & 0.13 & -0.01 to 0.26 & 0.02 & -0.02 to 0.08 & $0.15^{\S}$ & -0.00 to 0.29 & \\
\hline Financial security & $0.32 * * *$ & 0.18 to 0.47 & $0.03 *$ & 0.00 to 0.09 & $0.36^{* * *}$ & 0.21 to 50 & \\
\hline Functional health status & 0.10 & -0.04 to 25 & -0.01 & -0.08 to 0.02 & 0.09 & -0.07 to 0.24 & \\
\hline Sense of loneliness & $-0.28 * *$ & -0.45 to -0.09 & & & & & \\
\hline Sense of loneliness & & & & & & & 0.34 \\
\hline Family networks & $-0.34 * * *$ & -0.46 to -0.20 & & & & & \\
\hline Friends networks & $-0.29 * * *$ & -0.43 to -0.14 & & & & & \\
\hline Helping others & $-0.11 *$ & -0.22 to -0.00 & & & & & \\
\hline Use of community services & -0.01 & -0.15 to 0.11 & & & & & \\
\hline Age & $0.20 *$ & 0.04 to 0.38 & & & & & \\
\hline Gender & -0.05 & -0.20 to 0.10 & & & & & \\
\hline Financial security & -0.12 & -0.25 to 0.01 & & & & & \\
\hline Functional health status & 0.05 & -0.10 to 0.21 & & & & & \\
\hline
\end{tabular}

Notes: ${ }^{\S} p<0.06,{ }^{*} p<0.05,{ }^{* *} p<0.01$, and $* * * p<0.001$.

Abbreviations: $\mathrm{BC}$, bias-corrected; $\mathrm{Cl}$, confidence interval. 


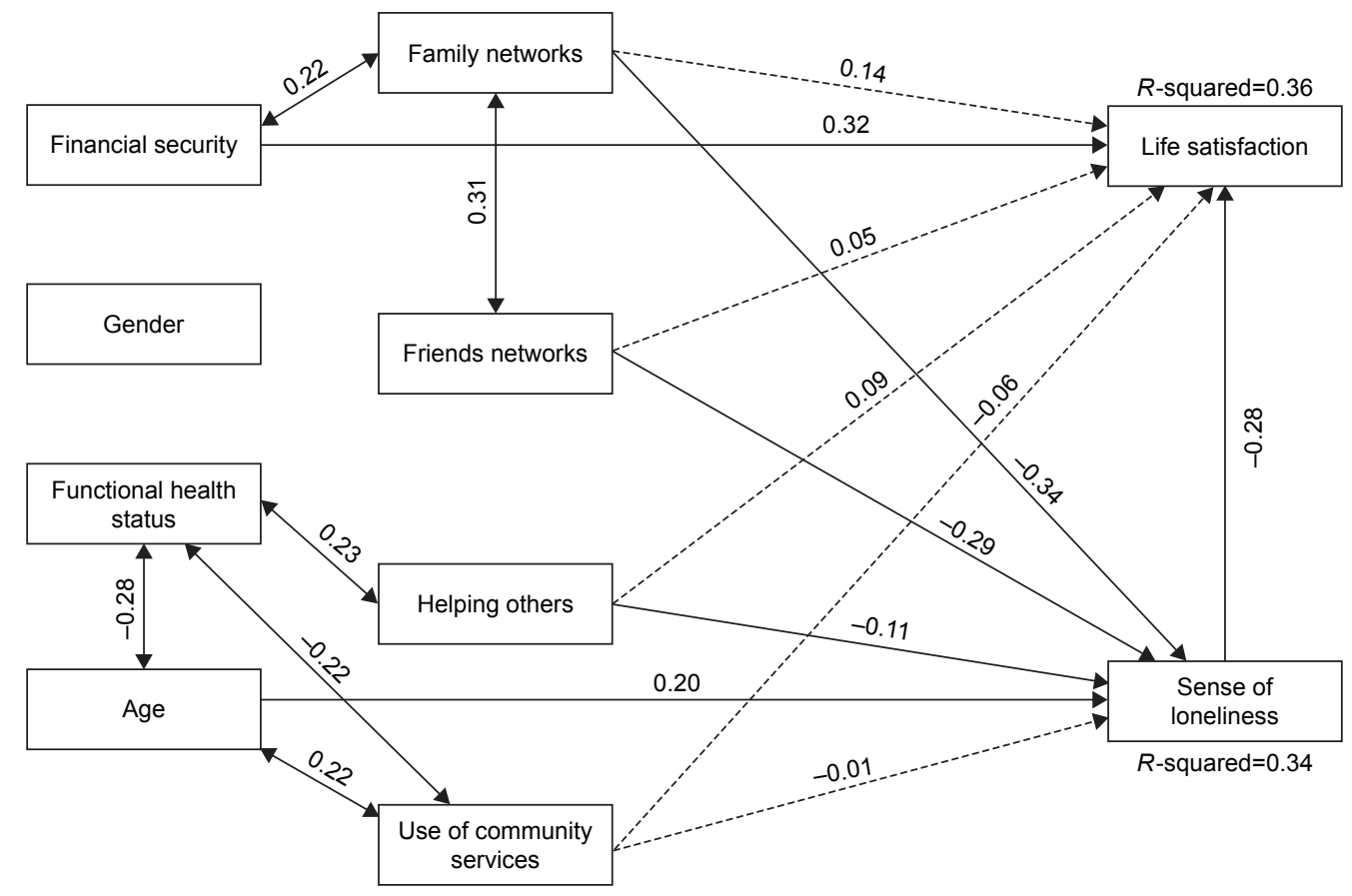

Figure I Path analysis of the effects of social support on life satisfaction through the sense of loneliness.

Notes: Beta values represent standardized path coefficients. Arrows with a single head represent direct effects. Arrows with two heads indicate correlations. Dashed lines indicate nonsignificant $(p>0.05)$ paths. Control variables are age, gender, financial security, and functional health status. The nonsignificant correlations between a) control variables (ie, age, gender, functional health status, and financial security), b) independent variables (family networks, friends networks, helping others, and use of community services) and c) control variables and independent variables were trimmed for a parsimonious model; while all the paths between control variables to dependent variables (ie, sense of loneliness and life satisfaction) were retained for model testing. However, for the purpose of simplicity, the nonsignificant paths between control variables and dependent variables were not shown in Figure 1.

Family networks (Beta $\mathrm{Bamily-sense} \mathrm{of} \mathrm{loneliness}=-0.34, p \leq 0.001$, BC bootstrap $95 \% \mathrm{CI}=-0.46$ to -0.20$)$, friends networks $\left(\right.$ Beta $_{\text {friend-sense of loneliness }}=-0.29, p \leq 0.001$, BC bootstrap $95 \% \mathrm{CI}=-0.43$ to -0.14$)$, and helping others (Beta $_{\text {helping-sense of loneliness }}=-0.11, p<0.05, \mathrm{BC}$ bootstrap $95 \%$ $\mathrm{CI}=-0.22$ to -0.00 ) were found to have negative direct effects on the sense of loneliness, and sense of loneliness had a statistically significant direct path to life satisfaction (Beta $_{\text {sense of loneliness-LS }}=-0.28, p<0.01, \mathrm{BC}$ bootstrap 95\% CI $=-0.45$ to -0.09$)$. One control variable, age, had a positive relationship with sense of loneliness ( Beta $_{\text {age-sense of loneliness }}=0.20$, $p<0.05$, BC bootstrap $95 \% \mathrm{CI}=0.04$ to 0.38 ).

The indirect effects of sources of social support on life satisfaction, mediated through sense of loneliness, were also significant. The results showed that sense of loneliness mediated the effect of support from family (Beta $_{\text {family-sense of lonelines-LS }}=0.09, p<0.01, \mathrm{BC}$ bootstrap 95\% $\mathrm{CI}=0.03$ to 0.18$)$, friends ( Beta $_{\text {friend-sense of loneliness-LS }}=0.08$, $p \leq 0.001$, $\mathrm{BC}$ bootstrap $95 \% \mathrm{CI}=0.03$ to 0.16 ), and helping others $\left(\right.$ Beta $_{\text {helping-sense of loneliness-LS }}=0.03, p<0.05$, BC bootstrap $95 \% \mathrm{CI}=0.00$ to 0.08 ) on life satisfaction. Similarly, sense of loneliness mediated the relationship of age and life satisfaction (Beta ${ }_{\text {age-sense of loneliness-LS }}=-0.06, p<0.01, \mathrm{BC}$ bootstrap $95 \% \mathrm{CI}=-0.14$ to -0.01$)$, and that of financial security and life satisfaction $\left(\mathrm{Beta}_{\mathrm{FS}-\mathrm{LS}}=0.32, p \leq 0.001, \mathrm{BC}\right.$ bootstrap $95 \% \mathrm{CI}=0.18$ to 0.47 ; Beta $_{\mathrm{FS}-\text {-sense of loneliness-LS }}=0.03$, $p<0.05$, BC bootstrap $95 \% \mathrm{CI}=0.00$ to 0.09 ).

\section{Discussion and implications}

The present study investigated the mediating effect of sense of loneliness on social support and life satisfaction among solitary Chinese older adults in Hong Kong, with a particular focus on the different sources and directions of social support. The results showed that sense of loneliness mediated the effects of family networks, friend networks, and helping others on life satisfaction; by contrast, the formal source of social support (represented by the use of community services) displayed no significant association with life satisfaction among solitary older adults.

The findings of the present study are consistent with those of a previous study that discovered a significant path between social support and subjective well-being through sense of loneliness among a sample of Chinese college students aged 17-25. ${ }^{2}$ The current study provided empirical support for the same phenomenon among older adults, and identified the varied pathways created because of the different sources 
and directions of social support that influence life satisfaction through the sense of loneliness. As indicated in Figure 1 and Table 3, social support from family and friends has significant indirect effects on life satisfaction through the sense of loneliness. This is consistent with the results of a previous study with a sample of 2,042 Spanish people. ${ }^{18} \mathrm{We}$, therefore, suggest that special attention should be paid to solitary older adults' peer networks, in addition to their familial contacts. To facilitate the expansion of friends networks for older adults, we recommend that the government provide more public places and facilities for older people to communicate with and meet friends; that communities organize low-cost interest classes and outings as socializing platforms for older adults to interact with more people of a similar age; and that tailored programs be created to foster older adults' alignment to social changes by equipping them with the knowledge and skills necessary to use computers, mobile phones, and other telecommunication devices to strengthen family and friend networks, thereby expanding their sources of social support. ${ }^{52,53}$

The current study also revealed that providing support to others was positively associated with optimal life satisfaction by alleviating the sense of loneliness, which echoes other scholars who have argued that achieving an altruistic goal is salient to promoting life satisfaction for older adults and that providing support to adult children or grandchildren could improve life satisfaction of older adults. ${ }^{21,54}$ Therefore, we suggest that awareness of the benefits of reciprocal support (ie, giving and receiving) for solitary older adults should be improved. We should remove the stereotype that the majority of older adults are frail and dependent on help from others. ${ }^{55}$ Service practitioners and policymakers should not assume that older adults only need to receive support; instead, volunteer programs should be developed for older adults in good health that enable them to engage in reciprocal support actions and enhance their quality of life.

However, inconsistent with previous findings, ${ }^{18}$ the present study discovered that access to formal support, represented by the use of community services, was not significantly associated with life satisfaction. One possible explanation is based on the traditional Chinese cultural values of filial piety and family care, which suggests that informal support from family members continues to play a more crucial role in caregiving for older people. In addition, according to the hierarchical compensatory model, ${ }^{56}$ caregiver preferences of older adults are based on how closely they are related to a caregiver; thus, formal care services may become their last resort, and are only used if the informal networks fail to provide adequate support. Therefore, the use of community services did not significantly increase the life satisfaction of the service users.

An alternative explanation is the need-dependent use of community services in Hong Kong. Although older adults who are frailer and exhibit higher degrees of functional impairment are more likely to be entitled to subsidized community and home care services, the life satisfaction of this group may be more difficult to improve. Moreover, due to the high turnover rate among community service providers in Hong Kong, it is challenging for older adults to develop strong emotional ties with formal care providers. Future community services should provide a more comfortable environment for older adults to foster emotional attachment and, thus, more appropriately supplement informal care. Because family structures, relationships, and values in Hong Kong are undergoing substantial changes, ${ }^{34}$ it is inevitable that people will expect more from formal support networks, instead of solely relying on family caregiving. Therefore, the government should be prepared to strengthen formal care services to facilitate a higher quality of life for older people. In addition, consistent with previous studies that have demonstrated socioeconomic inequality in later life well-being, 5,57-59 financial security was found to be positively associated with life satisfaction in the present study. Therefore, in addition to enhancing community care services, multipillar retirement protection schemes should also be strengthened to improve the financial status of older adults by providing them with sufficient cash and in-kind support. This may prevent solitary older adults from suffering in other domains of disadvantage, and encourage social participation, thereby enhancing their life satisfaction.

\section{Limitations}

This study had a few limitations. First, a cross-sectional design and comparatively small nonprobability sample were utilized. Although bootstrapping was applied to adjust for the smallsample bias, a larger representative sample or longitudinal sample could yield more convincing results. Second, because the participants were recruited from various senior service organizations and community centers in Hong Kong, they had some forms of social connections with others. Further research is needed to examine the situations of those solitary older adults with no access to formal services who are likely to be more disadvantaged in terms of sense of loneliness and life satisfaction. We should be cautious about generalizing and implementing the results of this study to the whole population of solitary older adults. Although the findings 
may have implications for adults in big cities in the People's Republic of China, or in other developed societies such as Singapore, Japan, or Taiwan, those who live in rural areas or in smaller cities much less prosperous than Hong Kong may present different patterns. Third, the present study relied solely on self-reports of life satisfaction and sense of loneliness, which can be subject to social desirability effects or recall bias. Finally, how different areas of social support, such as emotional, informational, and instrumental support, may affect sense of loneliness and life satisfaction of solitary older adults is yet to be examined. Future studies should analyze these unexplored factors to gain a holistic understanding of how support influences the quality of later life.

\section{Acknowledgments}

This work was supported by The Hong Kong Polytechnic University (grant numbers G-YBW3 and 1-ZVGD). We would like to thank Oi Ting Ho, Yan Lam Kwong, Yumi Sato, Wai Man Yim, and Wai Ying Yung for their assistance in data collection for this study.

This work was accepted for a paper presentation on interim findings at the 1st International Workshop on Active Ageing and Digital Inclusion in the International Symposium on Emerging Technologies for Education in 2016, and then for a poster presentation at the IAGG 2017 Conference. A short conference paper was published by $\mathrm{Wu}$ et al in Lecture Notes on Computer Science. The poster abstract was published in "Poster Abstracts" in Innovation in Aging.

\section{Disclosure}

The authors report no conflicts of interest in this work.

\section{References}

1. Diener E, Diener M, Diener C. Factors predicting the subjective wellbeing of nations. J Pers Soc Psychol. 1995;69(5):851-864.

2. Kong F, You X. Loneliness and self-esteem as mediators between social support and life satisfaction in late adolescence. Soc Indic Res. 2013;110(1):271-279.

3. Lue BH, Chen LJ, Wu SC. Health, financial stresses, and life satisfaction affecting late-life depression among older adults: a nationwide, longitudinal survey in Taiwan. Arch Gerontol Geriatr. 2010;50(Suppl 1): S34-S38.

4. St John PD, Mackenzie C, Menec V. Does life satisfaction predict fiveyear mortality in community-living older adults? Aging Ment Health. 2015;19(4):363-370.

5. Bai X, Guo Y, Fu YY. Self-image and intergenerational relationships as correlates of life satisfaction in Chinese older adults: will gender make a difference? Ageing Soc. 2017;1-18.

6. Meggiolaro S, Ongaro F. Life satisfaction among older adults in Italy in a gender approach. Ageing Soc. 2015;35(7):1481-1504.

7. Cohen S, McKay G. Social support, stress, and the buffering hypothesis: a theoretical analysis. In: Baum A, Taylor SE, Singer JE, editors. Handbook of Psychology and Health. Hillsdale, NJ: Erlbaum; 1984: 253-267.
8. Pinquart M, Sörensen S. Influences on loneliness in older adults: a metaanalysis. Basic Appl Soc Psychol. 2001;23(4):245-266.

9. Van Baarsen B. Theories on coping with loss: the impact of social support and self-esteem on adjustment to emotional and social loneliness following a partner's death in later life. J Gerontol B Psychol Sci Soc Sci. 2002;57(1):S33-S42.

10. Hsu HC, Chang WC. Social connections and happiness among the elder population of Taiwan. Aging Ment Health. 2015;19(12):1131-1137.

11. Chen J, Murayama S, Kamibeppu K. Factors related to well-being among the elderly in urban China focusing on multiple roles. Biosci Trends. 2010;4(2):61-71.

12. Gallagher EN, Vella-Brodrick DA. Social support and emotional intelligence as predictors of subjective well-being. Pers Individ Dif. 2008; 44(7):1551-1561.

13. Park S, Smith J, Dunkle RE. Social network types and well-being among South Korean older adults. Aging Ment Health. 2014;18(1):72-80.

14. Shen Y, Yeatts DE. Social support and life satisfaction among older adults in China: family-based support versus community-based support. Int J Aging Hum Dev. 2013;77(3):189-209.

15. Guo M. Parental status and late-life well-being in rural China: the benefits of having multiple children. Aging Ment Health. 2014;18(1):19-29.

16. Masi CM, Chen HY, Hawkley LC, Cacioppo JT. A meta-analysis of interventions to reduce loneliness. Pers Soc Psychol Rev. 2011;15(3): 219-266.

17. Lin N. Conceptualizing social support. In: Lin N, Dean A, Ensel WM, editors. Social Support, Life Events, and Depression. Orlando, FL: Academic Press; 1986:17-30.

18. Hombrados-Mendieta I, García-Martín MA, Gómez-Jacinto L. The relationship between social support, loneliness, and subjective well-being in a Spanish sample from a multidimensional perspective. Soc Indic Res. 2013;114(3):1013-1034.

19. Zimet GD, Dahlem NW, Zimet SG, Farley GK. The multidimensional scale of perceived social support. J Pers Assess. 1988;52(1):30-41.

20. Lowenstein A, Katz R, Gur-Yaish N. Reciprocity in parent-child exchange and life satisfaction among the elderly: a cross-national perspective. J Soc Issues. 2007;63(4):865-883.

21. Xu L, Wu B, Chi I, Hsiao HY. Intensity of grandparenting caregving and life satisfaction among rural Chinese older adults: a longitudinal study using latent difference score analysis. Fam Community Health. 2012; 35(4):287-299.

22. de Jong Gierveld J, Keating N, Fast JE. Determinants of loneliness among older adults in Canada. Can J Aging. 2015;34(2):125-136.

23. Netz Y, Goldsmith R, Shimony T, Arnon M, Zeev A. Loneliness is associated with an increased risk of sedentary life in older Israelis. Aging Ment Health. 2013;17(1):40-47.

24. Chen Y, Hicks A, While AE. Loneliness and social support of older people in China: a systematic literature review. Health Soc Care Community. 2014;22(2):113-123.

25. Adams KB, Sanders S, Auth EA. Loneliness and depression in independent living retirement communities: risk and resilience factors. Aging Ment Health. 2004;8(6):475-485.

26. Fokkema T, Naderi R. Differences in late-life loneliness: a comparison between Turkish and native-born older adults in Germany. Eur J Ageing. 2013;10(4):289-300.

27. Jakobsson U, Hallberg IR. Loneliness, fear, and quality of life among elderly in Sweden: a gender perspective. Aging Clin Exp Res. 2005;17(6): 494-501.

28. Zhang XJ, Sun L, Yu YL, Shen Q. Correlation between loneliness, family function and social support among elderly people. Chin J Clin Psychol. 2010;18:109-110.

29. Dong X, Chang ES, Wong E, Simon M. Perception and negative effect of loneliness in a Chicago Chinese population of older adults. Arch Gerontol Geriatr. 2012;54(1):151-159.

30. Arslantaş H, Adana F, Abacigil Ergin F, Kayar D, Acar G. Loneliness in elderly people, associated factors and its correlation with quality of life: a field study from Western Turkey. Iran J Public Health. 2015;44(1): $43-50$. 
31. Courtin E, Knapp M. Social isolation, loneliness and health in old age: a scoping review. Health Soc Care Community. 2017;25(3):799-812.

32. Bai X, Liu C, Baladon L, Rubio-Valera M. Multidimensional determinants of the caregiving burden among Chinese male caregivers of older family members in Hong Kong. Aging Ment Health. 2017:1-10.

33. Bai X, Lai DWL, Guo A. Ageism and depression: perceptions of older people as a burden in China. J Soc Issues. 2016;72(1):26-46.

34. Bai X. Development and validation of a multidimensional intergenerational relationship quality scale for aging Chinese parents. Gerontologist. Epub 2017 Oct 17.

35. Census and Statistics Department. 2011 Population census thematic report: older persons. Available from: http://www.census2011.gov.hk/ pdf/older-persons.pdf. Accessed March 20, 2017.

36. Chou KL, Ho AH, Chi I. Living alone and depression in Chinese older adults. Aging Ment Health. 2006;10(6):583-591.

37. Yuval-Davis N. Intersectionality and feminist politics. Eur J Women Stud. 2006;13(3):193-209.

38. Lai DWL, Bai X. Chapter 15. Social work with diverse older adults. In: Al-Krenawi A, Graham JR, Habibov N, editors. Diversity in Social Work in Canada. Toronto: Oxford University Press; 2016:345-372.

39. Chen Y, Feeley TH. Social Support, social strain, loneliness, and wellbeing among older adults: an analysis of the Health and Retirement Study. J Soc Pers Relat. 2014;31(2):141-161.

40. Tian Q. Intergeneration social support affects the subjective well-being of the elderly: mediator roles of self-esteem and loneliness. J Health Pscyhol. 2016;21(6):1137-1144.

41. Diener E, Emmons RA, Larsen RJ, Griffin S. The satisfaction with life scale. J Pers Assess. 1985;49(1):71-75.

42. Shi YZ. The development of elderly loneliness scale. J Family Educ. Bimonthy. 2008;16:74-95. Chinese.

43. Chi I, Yip PS, Chiu HF, et al. Prevalence of depression and its correlates in Hong Kong's Chinese older adults. Am J Geriatr Psychiatry. 2005; 13(5):409-416.

44. Lubben JE. Assessing social networks among elderly populations. Fam Community Health. 1988;11(3):42-52.

45. Leung DY, Leung AY, Chi I. An evaluation of the factor structure of the Instrumental Activities of Daily Living Involvement and Capacity scales of the Minimum Data Set for Home Care for elderly Chinese Community dwellers in Hong Kong. Home Health Care Serv Q. 2011; 30(3):147-159.
46. IBM Corp. Released 2012. IBM SPSS Statistics for Windows, Version 21.0. Armonk, NY: IBM Corp.

47. Arbuckle JL. IBM SPSS Amos 21 User's Guide. Crawfordville, FL: Amos Development Corporation; 2012.

48. Kim KH. The relation among fit indexes, power, and sample size in structural equation modeling. Struct Equ Modeling. 2005;12(3):368-390.

49. MacKinnon DP, Lockwood CM, Williams J. Confidence limits for the indirect effect: distribution of the product and resampling methods. Multivariate Behav Res. 2004;39(1):99-128.

50. Byrne BM. Structural Equation Modeling with AMOS: Basic Concepts, Applications, and Programming. New York: Routledge; 2013.

51. Hu C, Wang Y. Bootstrapping in AMOS, 2010. Powerpoint. Consulté le, 23-02. Available from: http://www3.nccu.edu.tw/ changya/SEMworkshop/ Amos_bootstrapping_20100630.pdf. Accessed April 24, 2017.

52. Bai X. Alignment or struggle? Exploring socio-demographic correlates of individual modernity modes in Chinese older people. Ageing Soc. 2016;36(1):133-159.

53. Li YT, Lee YC, Tsui MS, Pak MCM. The panel study of social support for middle-aged and elderly adults in Taiwan-Latent growth model. Int Soc Work. 2016. Available from: http://journals.sagepub.com/doi/ abs/10.1177/0020872816651696

54. Au A, Ng E, Lai S, et al. Goals and life satisfaction of Hong Kong Chinese older adults. Clin Gerontol. 2015;38(3):224-234.

55. Bai X. Image of ageing in society: a literature review. J Popul Ageing. 2014;7(3):231-253.

56. Cantor MH. Neighbors and friends: an overlooked resource in the informal support system. Res Aging.1979;1(4):434-463.

57. Kim JI, Kim G. Factors affecting the survival probability of becoming a centenarian for those aged 70 , based on the human mortality database: income, health expenditure, telephone, and sanitation. BMC Geriatr. 2014; $14: 113$.

58. Kim JI, Kim G. Social structural influences on healthy aging: communitylevel socioeconomic conditions and survival probability of becoming a centenarian for those aged 65 to 69 in South Korea. Int J Aging Hum Dev. 2015;81(4):241-259.

59. Read S, Grundy E, Foverskov E. Socio-economic position and subjective health and well-being among older people in Europe: a systematic narrative review. Aging Ment Health. 2016;20(5):529-542.
Clinical Interventions in Aging

\section{Publish your work in this journal}

Clinical Interventions in Aging is an international, peer-reviewed journal focusing on evidence-based reports on the value or lack thereof of treatments intended to prevent or delay the onset of maladaptive correlates of aging in human beings. This journal is indexed on PubMed Central, MedLine,

\section{Dovepress}

CAS, Scopus and the Elsevier Bibliographic databases. The manuscript management system is completely online and includes a very quick and fair peer-review system, which is all easy to use. Visit http://www.dovepress. com/testimonials.php to read real quotes from published authors. 